\title{
THE PROBLEM OF ETHICS AND GOD - THROUGH THE PHILOSOPHY OF A.N. WHITEHEAD AND K. NISHIDA
}

\author{
Eiko Hanaoka
}

\begin{abstract}
:
The differences between Nishida's and Whitehead's ethics are caused by the way of understanding God. In Nishida God is absolute nothingness, which means not only the negation of relativity, but also absolute negation of all substantial standpoints. In Whitehead God, created simultaneously with all nature, is an actual entity as the primordial creature by creativity. In this organic philosophy ethics becomes 'creative ethics'. I would like to enquire the new ethics on the ground of non-substantial God in Whitehead and Nishida. As the new ethics, adequate for the change from the last half of the 20th century until now, I would like to enquire into the ethics in Alfred North Whitehead (1861-1947) and Kitaro Nishida (1870-1945), in which new ethical possibilities are obtained.
\end{abstract}

\section{Both aspects of ethics and their origin}

Ethics can be classified into two kinds of ethics: the normative types of ethics, which assert their absoluteness, and the relative ethics, which cannot but be limited by experiences, historical and cultural situations in each time, place, state, country 
and so on. Moreover, ethics in the beginning of the 21 st century are different from that of the first half of the 20th century. The ethics since the latter half of the 20th century must think over not only the ethics of the relationship between various people, various races, states, but also significant new problems caused by the transplantation of organs etc., after brain death, by that of a living body based on the development of life medical science, environmental problems such as global warming caused by carbon dioxide emissions, and the problems of information ethics caused by the development of information technology. In this meaning only the normative ethics are, on the one hand, not enough. However, only the relative ethics on the base of the relative, historical cultural situation on the other hand are not be reliable, because in the latter case not only the responsibility, but also the desire for the power combined with violence is hidden.

We would like therefore to make clearer the merit and the demerit of the normative ethics and the relative ethics. First, the merit of the normative ethics is that behind the normative hides almost always the absolute being, like God or Buddha as the absolute, who commends the ethical law. Such ethics have a strong effectiveness for people who have faith in God or the absolute being. On the contrary the demerit of the normative ethics is that it has no effective power on people who have no faith, like contemporary young people, in substantial God or the absolute being.

Secondly, the merit of the relative ethics limited by the experiences of each time, each country, each history or each tradition etc, is that the ethics which are suitable for each situation are possible. On the contrary the demerits of the relative ethics are that the whereabouts of the responsibility is not clear, that the right and security of life and of each person and each thing can not be protected and that the earth and all nature in it will go to ruin with the various desires and above all the desire for power with violence.

We must therefore enquire into the new ethics, which abandon the demerits of both kinds of ethics and which succeed the merits of them. Such ethics are the ethics which consist in the origin of these two kinds of ethics. We can find such ethics in the ethics of A.N. Whitehead and that of K. Nishida. In both philosophies and ethics there is no substantial absolute being like God as creator and creativity is looked upon as of the utmost importance.

Whitehead thinks that God is created by "creativity" as one of the three categories of the ultimate including 'many' and 'one'. In Nishida God is the absolute nothingness, which means the absolute negativity, and this absolute negates its own negativity and works with love as agape and compassion which spurt out from the double negation. God in Nishida is non-substantial. In Whitehead the ethics 
are based on the "creativity" and can be propelled with the adventures of ideas. Their cores are truth, beauty, adventures and peace. In Nishida the core of his ethics is "the good", the pivot of which is the personality of the true self, which is common to all nature. In Whitehead's ethics "truth is the conformation of appearance to Reality, ${ }^{11}$ "beauty is the mutual adaptation of the several factors in an occasion of experience, ${ }^{\prime 2}$ and in truth the harmony between appearances as phenomena and reality is in beauty and the harmony between experiences and their factors are looked upon as most important. Peace in Whitehead means "harmony of Harmonies, "3 but neither impersonality nor tenderness according to Whitehead, because the former is too dead and the latter is too narrow, although both are very important.

Peace as harmony of harmonies in Whitehead is looked upon as that which completes the civilization as the origin of culture and civilization before him.

On the other hand, in Nishida's ethics the good as true self consists absolutely contradictorily self-identical in oneness with the world, and this good is the following experience in "the field of absolute nothingness", namely the experience of that "heaven and earth have a root and all nature are a body." ${ }^{4}$ Moreover, both philosophers have the same way of thinking over religion: Whitehead thinks that religion is world-loyalty ${ }^{5}$ and Nishida also thinks the ground of practical reason, namely of morality like in Kant as loyalty. ${ }^{6}$ In the ground of ethics of Whitehead and Nishida lies loyalty, namely loyalty as the core of religion.

It should also be noted that Nietzsche (1844-1900) regarded loyalty as "the will to the power" of the "weak" race Israel and despised "loyalty" which Christians took for the highest virtue in Christianity. However, loyalty in Whitehead and Nishida is taken for the origin of religion in the different dimension with Nietzsche's nihilistic standpoint of life, namely in the reiterated sense of this term "loyalty".

\section{The problem of motive and result in ethics}

First, in the ethics of feelings (German: Gesinnungsethik) like in Kant (17241804) it is important to act according to moral law and the result of its act is not

Alfred North Whitehead, Adventures of Ideas, The Free Press, New York, 1933, 241.

A.N. Whitehead, Adventures of ldeas, 252.

A.N. Whitehead, Adventures of Ideas, 285.

Nishida Kitaro's Complete Works, vol.1, Iwanami Press, 1965, 156.

A.N. Whitehead, Religion in the Making, Fordham Press, New York, 2005, 60.

Nishida Kitaro's Complete Works, vol. 11, 445. 
asked. The merit of such ethics is that, for example, in Kant the pureness of the motive of the action of the autonomous personality (that each person acts according to the moral law that man should act in order that "the maxim of the action of each person can always and simultaneously be applied as the principle of the universal law is perfect". However, the demerit of these ethics in these kinds of ethics is that they lack love as agape or compassion, humaneness or harmony of harmonies like in A. N. Whitehead. Moreover, the moral law as the absolute command has no power to be esteemed in the contemporary world, because people in this century have regrettably no faith in the absolute, ever if it were substantial or non-substantial. They only believe in immanent objective things.

Secondly, the ethics like Bentham (Jeremy - 1748-1832), which regards the result of the act as important, has merits in which the responsibility for the act can be made much of by the doer on the one hand. However, in the shadow of the utilitarian principle like for example, "the greatest happiness of the greatest number", the crisis of the pleasure, power or violence with power lies hidden, on the other hand, as the demerit of this ethics.

After we have understood the merits and demerits of ethics, which take either motive or result of action as important, we must now enquire into the new ethics in the origin of normative ethics like in Kant and utilitarian ethics like in Bentham. Such ethics suitable for the contemporary people, who respect not only feelings as heart and mind, but also the responsibility in the ethics, we can find in A.N. Whitehead and Nishida.

Almost all ethics until the first half of the 20th century was grounded on the base of the subject-object scheme, on which all nature was objectively observed as the object on the dimension of the third personal "I-it-relation", like in Martin Buber (1878-1965). On the contrary the ethics in Whitehead and Nishida are free from the subject-object-scheme, which has dominated the European traditional mainstream of the philosophy as metaphysics since Aristotle (384-322 B.C.) until Hegel (1770-1831). In the new ethics in Whitehead and Nishida feeling and will are the bases, but not the intellect separated from feeling and will. Besides these merits of the new ethics in both philosophers the "loyalty" as the core of religion takes root in both ethics. Religion in both philosophers does not mean the existing accomplished religions. Religion in Whitehead means "the world-loyalty," and that in Nishida is "the fact in the spirit," the core of which is "the loyalty," as stated above. In both ethics the logic is not subjective, but predicative, because in both

A.N. Whitehead, Religion in the Making, 60.

a Nishida Kitaro's Complete Works, vol.11, 371. 
philosophies there is no substantial absolute. God as non-substantial in the dimension of concrescence as process and God as an actual entity as reality in Whiteheadian philosophy, and God as oneness with phenomena as many in Nishida's philosophy, are very similar, only leaving the differences that in Whitehead the field of absolute nothing is not yet opened, in that in Whiteheadian philosophy the eternal object as the idea which means the form of the field of absolute nothingness plays an important role in the concrescence in his philosophy and ethics.

In both the ethics of Whitehead and Nishida the loyalty as the basis of religion, which can become a non-substantial eradicate, but not become the substantial subject, is also the origin of the ethics. The contents of the new ethics, the origin of which is the religion as "loyalty" like in both ethics in Whitehead and Nishida, are always different according to the situation of each time, each country, each race, each state, each person and so on. Whitehead gives sincerity as the first virtue in such an ethics, which Kierkegaard gives as "Ernst". Nishida gives the earnest wish for others (Japanese: Higan ${ }^{10}$ ) as the basis of loyalty, which he characterizes as the fundamental difference between Eastern culture and Western culture.

\section{Ethics and Society}

In ethics we must always think of the relation between ethics and society, because ethics is firstly needed in the society. In ethics in Whitehead and Nishida the problems of ethics and society are concerned with the problem of expression of experience. In Whitehead and Nishida the problem of society gives rise to the problem of "experience and its expression". According to Whitehead "expression [...] is the return from solitariness to society." II In Nishida "the problem of expression of experience" relates to the problem of society as "species", because in him the problem of "expression of experience" relates to the culture as form (Greek; eidos) which concerns the species.

First, Whitehead thinks that the originality is the very element in the expression of peculiar original persons which remains unformularized ${ }^{12}$ and suggests that to express the experience is creative. ${ }^{13} \ln$ Whitehead to express the basic experience

\footnotetext{
9 A.N. Whitehead, Religion in the Making, 5.

1 Cf. (6). Japanese "Higan" means "Vows resulting from the compassion of the Buddhas and bodhisattvas." (Japanese-English Buddhist Dictionary, Daito Shuppan-press, 1979, 105).

1) A.N. Whitehead, Religion in the Making, 137.

2.N. Whitehead, Religion in the Making, 136.

13 A.N. Whitehead, Process and Reality, The Free Press, A division of Macmillan Publishing, New York, 1929, 65.
} 
of loyalty in the case of change from philosophy to religion as basic of ethics is therefore the return to solitariness to society, as stated above.

In Nishida his "pure experience" as fundamental experience of the change from the ego to the true self, which is common to all nature, is the experience of the reality in the phenomenal world. However, in Nishida this fundamental experience of that "heaven and earth have the same root and all things are one body", is always expressed as the world of logic of the truth as reality. To borrow the term in Hua-yen-tsung (Japanese: Kegon-shu), in Nishida the experience of the selfawareness of the world in which phenomena influence one another without hindrance" (Japanese: "iiii-muge-hokkai") is always once more expressed as "the world in which phenomena are identified with noumena" (Japanese: "riii-mugehokkai"). This can be understood from the fact that he always discusses the problem of expression and expressing action since he wrote his treatise "expressing action" (1925) before he advocates his "logic of the field of absolute nothingness". We often hear the critique that the logic of the field of absolute nothingness in Nishida lacks the logic of species or the consideration of society, although the oneness between self and world is very deeply thought of. However, he seems to have thought always the problem of society with regards to the ethics in the problem of expression of fundamental experience.

As discussed above, the new ethics suitable for the 21 st century are such that that they are grounded on the base of the religion as loyalty (as feeling and will), namely on the personality, the core of which is non-substantial sincerity and the earnest wish for others, but not in existing religions until now.

\section{The Relation of God to Ethics}

According to the discussion from Chapter I to Chapter III, which I read at the 30th Anniversary Conference of "the Japan Society for Process Studies in Aomori Public College last October, it became clear that ethics in A.N. Whitehead (1861 - 1947) and K. Nishida (1870-1945) is founded on the ground of religion, the core of which is "loyalty". We know of course, that Schleiermacher (1768-1834) separated religion from metaphysics and ethics, and he founded the originality of religion in intuition and feeling. According to Schleiermacher the religion is "the intuition of the universe and "the feeling of absolute dependence" (In German: das Gefuehl schlechthinniger Abhaengigkeit). Kant also asserted the independent sphere of religion inside simple reason, which is separated from theoretical reason which is concerned with logic, practical reason which is concerned with ethics or morals and the power of judgment which is concerned with art. Since Kant, other than Nishida and Whitehead ethics and religion has been dealt with as an almost separate sphere. 
However, in the $21^{\text {st }}$ century we must deal with the contemporary moral or ethical problems not only in the domain of mere ethics or mere morals, but also in the new ethics the basis of which consists in religion like in K. Nishida and A.N. Whitehead. I would like, therefore, to discuss about the relation between ethics and the way of understanding God, which is dealt with in each religion.

It seems to me that ethics can not but change according to the ways in which God is understood. There are many ways in which God in each religion is understood. So I would like to classify the ways of understanding God for the present into two ways, namely the way of understanding God as substantial God and the way of understanding God as non-substantial. In K. Nishida and A.N. Whitehead God is understood as non-substantial. Substantial God as in Christianity and in Islam or substantial Buddha as in Pure-land Buddhism cannot be applied in the case of Nishida and Whitehead. Both philosophers understand God as non-substantial. In each religion, in which God is substantial, man can have, so to speak, canonical ethics like the sermon and the Ten Commandments in Christianity or Buddhist commandments. In these cases the ethics can be canonical. However, in the $21^{\text {st }}$ century God cannot be substantial, because people until the end of World War II on the ground of substantial God could not but fall into nihilism, in that substantial God had brought about only intellectual, objective, abstractive, reasonable calculation and technology against the subjective, concrete, experimental reality on the ground of will and feeling, and man could not but to fall into nihilism, without finding out meaning, significance, aim and value by living. Moreover, since almost all Christians could not help Jews, who were exiled out of Germany by Nazism in World War II, none of us can believe in canonical ethics.

Then, which God is in Nishida and Whitehead? God in Nishida is God as absolute nothingness. God in Whitehead is God, who was created by creativity as one of three ultimate categories in his organic philosophy. So, I would like to inquire into, how the ethics become different between Nishida and Whitehead, in that each philosopher understands God in a different way, although both of them understand God commonly as non-substantial.

\section{The Relation of God to Ethics in A.N. Whitehead}

\section{(a) God in A.N. Whitehead}

God in Whiteheadian organic philosophy is God as primordial creature by creativity as one of the three ultimate categories at the same time with all other actual entities, namely as an actual entity, but neither before nor after all other actual entities. 
Moreover, God in his philosophy is self-causative (in Latin: causa sui) like each other actual entity in this universe.

The first phase of a new conçrescence of each original actual entity and a character of creativity is God as an actual entity. In this meaning God in Whitehead is included in the community of all actual entities, which mean the primordial actual entity called "God" and the temporal actual entities. ${ }^{14}$ Nevertheless, eternal objects as a category of existence, listed in the beginning of his book Process and Reality, are not created by God. ${ }^{15}$ The reason is that the nature of God requires eternal objects in the same degree that eternal objects require God. God is the foundation of the relation of eternal objects, and eternal objects abstracts from all determinate actual entities, including even God. Thereupon the three natures of God come into question.

According to the organic philosophy in Whitehead there are three natures in God: the primordial nature of God, the consequent nature of God and the superiective nature of God. The primordial nature of God is the acquirement by creativity of a primordial character, ${ }^{16}$ and the unlimited conceptual realization of the absolute wealth of potentiality. ${ }^{17}$ Moreover, this nature of God is the lure for feeling, the eternal urge of desire. ${ }^{18}$ The consequent nature of God as the contrary pole of the primordial nature of God in Whiteheadian philosophy is the meaning of God's physical feeling upon his primordial concepts. ${ }^{19}$ The primordial nature of God is free, complete, primordial, eternal, actually deficient, and unconscious. The consequent nature of God is determined, incomplete, consequent, everlasting, fully actual, and conscious.

The superjective nature if God is "the character of the pragmatic value of his specific satisfaction qualifying the transcendent creativity in the various temporal instances. ${ }^{\text {20 }}$ In other words the primordial nature of God is "the concrescence of a unity of conceptual feeling, including among their data all eternal objects. ${ }^{\prime 21}$ The consequent nature of God is "the physical prehension by God of the actualities

\footnotetext{
14 A.N. Whitehead, Process and Reality, 257.

15 A.N. Whitehead, Process and Reality, 344.

16 A.N. Whitehead, Process and Reality, 343.

17 A.N. Whitehead, Process and Reality, 344.

18 A.N. Whitehead, Process and Reality, 345.

19 A.N. Whitehead, Process and Reality, 88.

A A.N. Whitehead, Process and Reality, $87 f$.

21 A.N. Whitehead, Process and Reality, 88.
} 
of the evolving universe. ${ }^{22}$ God in Whiteheadian organic philosophy therefore means the outcome of creativity, the foundation of order and the goad towards novelty and it has the character of the pragmatic value.

\section{(b) The relation of God to ethics in Whitehead}

I would like to think over the relation of God in Whitehead to ethics which always is simultaneously the outcome of creativity as one of three ultimate categories in him, the foundation of order and the goad towards novelty. First, God created by creativity as one of three ultimate categories in Whitehead is quite different from Christian God as creator. God created by creativity in him cannot command canonical ethics for human beings and all nature. Instead of canonical ethics God created by creativity in him promotes living creatively, because the creativity as a ultimate category in Whitehead will only be able to let human beings and all nature be creative.

However, God in Whitehead simultaneously is the foundation of order, because God works also so, as the consequent nature of God. God as the foundation of order can therefore found order for all nature. Moreover, God as the foundation of order simultaneously is the goad towards novelty, because God works also as the superjective nature of God, which qualifies the transcendent creativity in the various temporal instances. In this meaning God in Whitehead is the origin of novelty in all nature. God in Whitehead therefore is, to bring it to a conclusion, originally concerned with creativity, order and novelty including pragmatic value, although God in him is not creator like in Christianity. It is a remarkable difference from Christianity that God is distinct from eternal objects as one of the eight categories of Existence in Whitehead. Eternal objects in Whitehead are "Pure Potentials for the Specific Determination of fact." ${ }^{23}$ Further, God's nature requires eternal objects to the same degree that eternal objects require God's nature, as stated above.

Now, eternal objects in Whitehead seem to be the definite form of "chora", namely the form as idea of the self-awareness of self and world. "24 Greek "chora" in "Timaeus" by Plato means "field", and Whitehead talks about it in his book "Adventure of Ideas." ${ }^{25}$ And yet Nishida also advocated his God as "the field of

2 A.N. Whitehead, Process and Reality, 88.

23 Eiko Hanaoka, "Zen and Christianity - From the Standpoint of Absolute Nothingness", Maruzen Kyoto Publication Service Center, 2008, 437.

24 Cf. A.N. Whitehead, Adventures of ldeas, 187.

25 Ruth F. Sasaki, The Record of Lin-chi, The Instifute for Zen Studies, Kyoto, Japan, 1975, 5. 
absolute nothingness" on the ground of "chora" in Timaeus by Plato. Both Whitehead and Nishida advocated each new epochal way of thinking on the same term "chora" in Plato. One of the differences in both philosophers on the same ground of "chora" in Plato is that in Whitehead the definitive form as idea of "chora" is "eternal objects" and that in Nishida "chora" is "the field of absolute nothingness", which subsumes all nature and is looked upon God as function. In Whitehead it is understandable from the above mentioned discussion, that the primordial nature of God includes all eternal objects in the occasion of concrescence of a unity of conceptual feelings among their data. On the contrary God in Nishida can be understood as an ultimate category "creativity" in Whitehead. God in Whitehead is completely different from creativity in Whitehead.

From the above-mentioned inquiry it is evident that God in Whitehead is not what commands canonical ethics, so far as God in Whitehead is that which was created by creativity at the same time with each of all nature. Nevertheless, this God in Whitehead is what can lure each actual entity of all nature, nexus or society into the ethics, which is the ethics on the ground of "loyalty for the world" as the core of religion, as mentioned above, so far as God in Whitehead is the foundation of order and the goad towards novelty, in short the lure for feeling as the core of organic philosophy. Such ethics in Whitehead becomes that which always is shaken by creativity, which corresponds to God as absolute nothingness in Nishida, and is corrected by it. Such ethics therefore is not the ethics in which each of all nature can act in oneness with creativity as an ultimate category in Whitehead. In such ethics creativity as a category in Whitehead is superior to an individual.

\section{The Relation of God to Ethics in K. Nishida}

\section{(a) God in K. Nishida}

In "the Inquiry into the Good" by Nishida, which is the main work of his earlier works, God is understood as the unifier and the non-substantial foundation of cosmos. Since Nishida advocated "the logic of the field of absolute nothingness" (1926), in that he had a hint for his logic from the term "chora" in "Timaeus" by Plato, Nishida took God for "the field" (= openness) as "absolute presence". In him God is "absolute nothingness" as absolute negativity of substantiality. In the field of absolute nothingness as "absolute infinite openness" in Nishida each of all nature is an absolute center and simultaneously only a point of the periphery, which builds the world and cosmos. In such an "openness" or "absolute presence" "the individual and the field (= openness)" or "the individual and the world" can be self-identical, although they are expressed "absolutely contradictorily self- 
identical" in the objective logic. In such a field (= openness) each of us can say, I am the field (= openness), and the field (=openness) is I, because the field (= openness) and I were non-substantial. In this case there are no eternal objects as potentialities between individual and field (chora) or "individual and the world", which can be understood as a kind of form of "chora" like in Whitehead.

In Whitehead "creativity" as a category of three ultimate categories in him, which created God with all nature at the same time, can, it seems to me at least, correspond to "the field of absolute nothingness" and therefore to God as absolute nothingness.

The relation of God, as above-mentioned, as the absolute negation of substantiality of each of all nature and of standpoints, to ethics consists in the self-awareness in each of all nature. That is to say, the self-awareness of self of each person in the field of absolute nothingness means that the world becomes aware of the true world in each individual, and that ethics in Nishida can consist on the ground of the true self-awareness of self and world.

\section{(b) The Relation of God to Ethics in K. Nishida}

In Nishida God is absolute nothingness, and such God is each of our individuals as true self and vice versa, as mentioned briefly above. In the logic of the field of absolute nothingness the relation of God to ethics means to live in the self-awareness of true self of each individual. The reason being that in Nishida the good means to become to true self, and to live as true self common to each of all nature is looked upon as ethics. Such ethics in Nishida consists in the basis of religion. Because, while in Nishida the religion is taken "for the fact in the spirit", and to be able to understand that "the fact in the spirit" is religion it is required that each of individuals tries to make efforts to live in true self-awareness. In the ethics on the basis of religion as loyalty in the true self-awareness each individual can be absolutely contradictorily self-identical with the field of absolute nothingness, although the individual and the field of absolute nothingness are expressed absolutely . contradictorily self-identical in the objective logic. In this ethics in Nishida there is no difference with regard to superiority between "the individual and the field". In this ethics "the individual and the field" or "the individual and the world" can be equivalent.

\section{Conclusion}

So long as "chora" is taken for eternal objects as form (= idea), even if potentialities, ethics as creative act of each person is not so easy, and each person cannot completely get out of the crisis to fall into the being, who only obeys, so to speak, 
the commands from the creativity as a category of three ultimate categories. According to the words of Lin-chi ethics in Whitehead is for people, who "endlessly are on the way, yet have never left home" and ethics in Nishida is for people, who "have left home, yet are not on the way." According to the words from "Vajrasutra" (= the Diamond Sutra) that each individual can live in the true heart and mind, when he/she has no home to live in". It seems to be important that we in the $21^{\text {st }}$ century ultimately inquire into ethics of self-awareness in the field of absolute nothingness. 